\title{
Dynamic Modeling on Nitrogen Assignment in Tobacco
}

\author{
Peng Zhao, Yuanyuan Shi, Xinming Ma*, and Shuping Xiong \\ Henan Key Laboratory for Regulating and Controlling Crop Growth and Development, \\ Henan Agricultural University, Zhengzhou, P.R. China \\ zhpddy@163.com, xinmingma@126.net
}

\begin{abstract}
Many external and internal studies in based on the relevant literature and consult to tobacco experts, based on the experimental research of the years between 2004 and 2005, the basic model of soil- $\mathrm{N}$ of distribution was developed after analysising the content of nitrogen in the whole plant of tobacco. The model is designed to simulate dynamically absorption and distribution of nitrogen for tobacco. The diversification of nitrogen in tobacco is exhibited dynamically in the form of curve which originates from the software of Visual Basic 6.0. The result showed that the simulated value of nitrogen content is not remarkably different from the measured value in root, stem and leaf of tobacco in the level of 0.05 , and the simulation value of nitrogen content fit the measured value very well in the model. It proveds a concerning modulus of 0.9934 that the 1:1 graphical comparison between simulation value and measured data of nitrogen content in tobacco leaf. The simulated and the measured agreed perfectfull. The model helps to forecast and conduct the management of nitrogen fertilizer in tobacco field.
\end{abstract}

Keywords: Tobacco, Nitrogen, Assignment, Model.

\section{Introduction}

Tobacco is one of the important cash crops. Nitrogen is the most significant nutritious element to tobacco, and it has remarkable influences on tobacco's growth and development as well as yield and quality. Either insufficiency or redundancy of nitrogen affects the output and quality of tobacco. An appropriate supply of nitrogen can ensure the normal growth of the plant and the premium yield of tobacco leaves as well as good quality of the leaves[1-4]. The distribution of nitrogen in the whole plant is of great significance; it directly influences the quality of tobacco leaves. The proportion of distribution of nitrogen in root, stem and leaves is leaves $>$ stem $>$ root. Different growing positions of leaves can directly affect the whole content of nitrogen[5]. The total accumulation of the amount of nitrogen of leaves in different leaf positions is middle leaves $>$ upper leaves $>$ lower leaves[6]. During the maturity process of fluecured tobacco, the nitrogen accumulation amounts and distribution proportion of stem

\footnotetext{
* Corresponding author.
} 
increase and the nitrogen accumulation amounts and distribution proportion of leaves decrease[7].

In the field of crop, visual simulation models of crops have been developed. The models can also simulate nitrogen dynamic. There are CERES, ORYZA and WHEATGRO at abroad[8-10]. In China, GaoLiangzhi[11] has developed RCSODS; Cao Hongxin[12] has explored simulation-optimization for wheat population, soil moisture and nitrogen dynamic. Predecessors mainly focus on wheat, corn and rice, but seldom focus on tobacco. Based on the dynamic simulation of tobacco's absorption and distribution of nitrogen, this research aims to provide scientific foundation for the improvement of the quality of tobacco through the appropriate utilization of nitrogenous fertilizer.

\section{Materials and Method}

\subsection{Materials}

The materials of the research mainly come from experimental research in the fields, relevant literature and consult to tobacco experts. They are mainly used to fix the parameter of the model and to verify the model.

\subsection{Field Experiments}

Experiment I was carried out from 2004 to 2005 in Science and Education Institute of HAU. The tested variety was Zhongyan101. It was sowed on March $5^{\text {th }}$, and transplanted on May $1^{\text {st }}$. The tested soil was sandy soil. The proportion of the organic substance of the soil was $0.89 \%$; the content of the nitrogen was $0.669 \mathrm{~g}^{\circ} \mathrm{kg}^{-1}$; the content of available phosphorus was $14.25 \mathrm{mg} \bullet \mathrm{kg}^{-1}$ and the content of available potassium was $70.21 \mathrm{mg} \bullet \mathrm{kg}^{-1}$. $\mathrm{pH}$ value was 8.1 . The tobacco was cultivated in pots. Each pot was filled with $30 \mathrm{~kg}$ dry soil. The amounts of nitrogenous fertilizer were set at three levels: $0 \mathrm{~kg} \bullet \mathrm{hm}^{-2}, 45 \mathrm{~kg} \bullet \mathrm{hm}^{-2}$ and $90 \mathrm{~kg} \bullet \mathrm{hm}^{-2}$. The amounts were repeated three times and 30 plants were dealt with at one time. In the nitrogenous fertilizer, the proportion of nitrogen in nitric form and in ammonium form was both $50 \%$; the amounts of $\mathrm{P}_{2} \mathrm{O}_{5}$ and $\mathrm{K}_{2} \mathrm{O}$ were respectively $45 \mathrm{~kg} \cdot \mathrm{hm}^{-2}$ and $90 \mathrm{~kg} \bullet \mathrm{hm}^{-2}$. $\mathrm{KHNO}_{3}$ and $\left(\mathrm{NH}_{4}\right)_{2} \mathrm{SO}_{4}$ were used as nitrogenous fertilizer; $\mathrm{Ca}\left(\mathrm{H}_{2} \mathrm{PO}_{4}\right)_{2}$ was used as phosphate fertilizer and $\mathrm{KHNO}_{3}$ and $\mathrm{K}_{2} \mathrm{SO}_{4}$ were used as potash fertilizer. Experiment II was carried out in Fenchen Town, Xiangcheng County, Henan Province. The tested variety was Zhongyan101. It was sowed on March $1^{\text {st }}$ and transplanted on April 25th. The growing method was the same as Experiment I . The tested soil was sandy clay.

In the soil, the proportion of the organic substance was $1.25 \%$; the content of nitrogen was $0.925 \mathrm{~g} \bullet \mathrm{kg}^{-1}$; the content of available phosphorus was $16.24 \mathrm{mg} \mathrm{kg}^{-1}$ and the content of available potassium was $78.46 \mathrm{mg} \mathrm{kg}^{-1}$. $\mathrm{pH}$ value was 7.6 . 


\subsection{Measuring Method}

The means of measuring the whole content of nitrogen in tobacco plant: to take the roots, stems and leaves of the tested tobacco at the respective periods of 30days, 45days, 60 days 75days, 90days and 105days after transplantation. Then dried at the temperature of $105{ }^{\circ} \mathrm{C}$ and the content of nitrogen in the roots, stems and leaves measured by semi-microkjeldahl[13].

\section{The Description of the Model}

\subsection{The Description of the Absorption of Nitrogen by Roots}

The nitrogen tobacco needed was mainly absorbed by roots. The model didn't take other ways of absorption such as leaves spraying into consideration. Supposing all the nitrogen was absorbed by roots.

The total uptake of nitrogen equalized the crop' s minimum requirement for nitrogen plus the small supplier of nitrogen in the maximum amount of soil.

$$
\text { TNUP=MIN(NDEML+NDEMST+NDEMRT, ANSL / DELT) }
$$

ANSL represented the available nitrogen in the soil; ANSL / DELT stood for the total available nitrogen in a time step; DELT in the model was usually one day. The available content of nitrogen in the soil on the first day after growing was as follows:

Initial available nitrogen in the soil was $\operatorname{ANSL}(0)=\mathrm{ANSLO}+\mathrm{AFA} \times \mathrm{FNC} \times \mathrm{RF}$.

ANSL0 represented available nitrogen in the soil without utilizing nitrogenous fertilizer; AFA represented the amount of nitrogenous fertilizer not utilized; FNC represented the content of nitrogen in the nitrogenous fertilizer; RF represented the ratio of the utilization of the fertilizer. ANSLO can be calculated by the dynamic model of nitrogen's circulation in the soil; it can also be fixed by statistics from experiment in the fields. The latter means is easy and direct. The method was using the content of nitrogen absorbed by the whole plant during the whole growing period without using fertilizer to divide the whole days of the growing period. The model was as follows: .Nu represented the content of nitrogen absorbed during the whole growing period in the soil without utilizing fertilizer. Dsum represented the whole days of the growing period.

\subsection{The Description of the Distribution of Nitrogen}

The nitrogen absorbed by the root was distributed to root, stem and leaves. The quantity of nitrogen absorbed by the plant was changing with its growing periods. What's more, the whole content of nitrogen that the organs held was different in different growing periods. Thus the whole content of nitrogen that contained by different organs was in obvious evolutionary patterns. 
Supposing the whole content of nitrogen absorbed by root from the soil was distributed according to the requirement of the organs, then index of distribution in the organs was as follows:

$$
\begin{aligned}
\mathrm{NCPL} & =\mathrm{NDEML} /(\mathrm{NDEML}+\mathrm{NDEMST}+\mathrm{NDEMRT}) \\
\mathrm{NCPST} & =\mathrm{NDEMST} /(\mathrm{NDEML}+\mathrm{NDEMST}+\mathrm{NDEMRT}) \\
\mathrm{NCPRT} & =\mathrm{NDEMRT} /(\mathrm{NDEML}+\mathrm{NDEMST}+\mathrm{NDEMRT})
\end{aligned}
$$

NCPL represented the index of distribution of nitrogen in the leaves; NCPST represented the index of distribution of nitrogen in the stem; NCPRT represented the index of distribution of nitrogen in the root; NDEML represented the content of nitrogen required by the leaves; NDEMST represented the content of nitrogen required by the stem and NDEMRT represented the content of nitrogen required by the root.

The accumulation ratio of the content of nitrogen of each organ was calculated through the index of distribution of nitrogen in the organ multiplied the whole content of nitrogen absorbed by the root (TNUP, $\mathrm{kg} \bullet \mathrm{hm}^{-2} \bullet \mathrm{d}^{-1}$ ). The formula was:

$$
\begin{gathered}
\text { NUPL }=T \text { TUP } \times \text { NCPL } \\
\text { NUPL }=T \text { NUP } \times \text { NCPL } \\
\text { NUPRT }=T N U P \times N C P R T
\end{gathered}
$$

NUPL stood for the accumulation ratio of the content of nitrogen in the leaves; NUPST stood for the accumulation ratio of the content of nitrogen in the stem and NUPRT stood for the accumulation ration of the content in the root. Then the amount of nitrogen required by each organ at any time was:

$$
\text { NDEML }=(\mathrm{WLV} \times \mathrm{XNCEL}-\mathrm{ANLV}) / \mathrm{TC}
$$

WLV, WST, and WRT were net weight of the leave, stem and root. XNCST, XNCST and XNCRT were the maximum nitrogen volume ( $\mathrm{kg} \mathrm{N} / \mathrm{kg}$ non-carbon substance) of the leave, stem and root, respectively which vary with different growing periods. ANLV, ANST and ANRT were the actual nitrogen volume of the leaves, stem and root. TC was the corresponding time coefficient which was usually one day in the model of plant growing. XNCL was the model's input coefficient. XNCST and XNCRT can be ascertained by the following formulas:

$$
\begin{aligned}
& \mathrm{XNCST}=0.5 \times \mathrm{XNCL} \\
& \mathrm{XNCRT}=0.5 \times \mathrm{XNCST}
\end{aligned}
$$

Based on the empirical data of the year 2004 and 2005(Table 1), and considering the influence of tobacco plant's nitrogen situation on the index of nitrogen distribution, the dynamic distribution index of tobacco plant's nitrogen situation was simulated. 
Table 1. The change of nitrogen distribution index

\begin{tabular}{cccc}
\hline Day after translate & Root & Stem & leaf \\
\hline 30 & 33.3 & 30.0 & 36.7 \\
45 & 33.7 & 25.3 & 41.1 \\
60 & 29.8 & 26.6 & 43.6 \\
75 & 30.4 & 27.5 & 42.2 \\
90 & 31.8 & 32.8 & 35.4 \\
105 & 30.5 & 46.4 & 23.1 \\
\hline
\end{tabular}

\section{The Model's Exploration Tool and Operation Environment}

The system was developed on the operation stage of Windows 2000 with PIV 1.8GCPU and 256MB internal memory. The software of Access 2003 was used to design data basis, the dominant part and user interface of Chinese version Visual Basic 6.0. The system was configured by auto structure software. Each constituent part can be used either separately or linked with other component parts flexibly and conveniently. All these made the system interface concise and clear and easy to be operated.

\section{Verification of the Model}

According to the physical and chemical properties together with the cultivation condition of the soil in Zhengzhou City and Xiangcheng County, first, the module of the distribution of nitrogen was used to simulate the distribution of nitrogen in the whole plant during the growing period, both the tobacco in Zhengzhou and the tobacco in Xiangcheng were used to simulate. The study selected Zhongyan101 as the representative, making a comparison between simulation and observation of root nitrogen rate.

Table 2. Comparison between simulation and observation of root nitrogen rate $\left(\mathrm{kghm}^{-2}\right)$

\begin{tabular}{|c|c|c|c|c|c|c|c|c|}
\hline \multirow{3}{*}{$\begin{array}{l}\text { Day after } \\
\text { translate }\end{array}$} & \multicolumn{4}{|c|}{ Xiangcheng } & \multicolumn{4}{|c|}{ Zhengzhou } \\
\hline & \multicolumn{3}{|c|}{ Prediction Observation Differential } & \multirow[t]{2}{*}{$\mathrm{Xc}^{2}$} & \multicolumn{3}{|c|}{ Prediction Observation Differential } & $\mathrm{Xc}^{2}$ \\
\hline & value & data & value & & value & data & value & \\
\hline 30 & 1.1 & 1.07 & 0.03 & 0.2068 & 0.84 & 0.8 & 0.04 & 0.2642 \\
\hline 45 & 3.69 & 3.62 & 0.07 & 0.0521 & 3.28 & 3.19 & 0.09 & 0.0518 \\
\hline 60 & 12.68 & 12.56 & 0.12 & 0.0117 & 11.15 & 11.14 & 0.01 & 0.0218 \\
\hline 75 & 11.72 & 11.77 & -0.05 & 0.0173 & 10.2 & 10.21 & -0.01 & 0.0237 \\
\hline 90 & 13.91 & 14.01 & -0.1 & 0.0112 & 9.29 & 9.28 & 0.01 & 0.0260 \\
\hline 105 & 15.22 & 15.67 & -0.45 & 0.0002 & - & - & - & - \\
\hline $\mathrm{Xc}^{2}$ & & & & 0.2992 & & & & 0.3875 \\
\hline
\end{tabular}


Table 2 showed the comparison between simulation and observation of root nitrogen rate. It can be worked out that $\mathrm{X} 0.05,5^{2}=9.89>\mathrm{Xc}^{2}(0.2992,0.3875)$, which revealed that at the level of 0.05 , the differential value was not significant; showing that the simulation and observation of root nitrogen rate fit well through the model.

Table 3 showed the comparison between simulation and observation of stem nitrogen rate. It can be worked out that $\mathrm{X} 0.05,5^{2}=9.89>\mathrm{Xc}^{2}(0.1760,0.1681)$, which revealed that at thelevel of 0.05 , the differential value was not significant; that is to say, the simulation and observation of stem nitrogen rate fit well through the model.

Table 3. Comparison between simulation and observation of stem nitrogen rate

\begin{tabular}{ccccccccc}
\hline \multirow{3}{*}{$\begin{array}{c}\text { Day after } \\
\text { translate }\end{array}$} & \multicolumn{3}{c}{ Xiangcheng } & \multicolumn{5}{c}{ Zhengzhou } \\
\cline { 3 - 10 } & value & data & value & & value & data & value \\
\hline 30 & 2.25 & 2.25 & 0 & 0.1129 & 2.31 & 2.3 & 0.01 & 0.1024 \\
45 & 6.64 & 6.66 & -0.02 & 0.0348 & 4.69 & 4.66 & 0.03 & 0.047 \\
60 & 21.83 & 21.86 & -0.03 & 0.0102 & 23.49 & 23.44 & 0.06 & 0.0084 \\
75 & 25.64 & 25.63 & 0.02 & 0.0092 & 22.59 & 22.69 & -0.1 & 0.0072 \\
90 & 40.25 & 40.23 & 0.02 & 0.0056 & 42.2 & 42.34 & -0.14 & 0.0031 \\
105 & 47.01 & 47.13 & -0.11 & 0.0032 & - & - & - & - \\
$\mathrm{Xc}^{2}$ & & & & 0.176 & & & & 0.1681 \\
\hline
\end{tabular}

Table 4. Comparison between simulation and observation of leaf nitrogen rate

\begin{tabular}{|c|c|c|c|c|c|c|c|c|}
\hline \multirow{3}{*}{$\begin{array}{l}\text { Day after } \\
\text { translate }\end{array}$} & \multicolumn{4}{|c|}{ Xiangcheng } & \multicolumn{4}{|c|}{ Zhengzhou } \\
\hline & \multicolumn{3}{|c|}{ Prediction Observation Differential } & \multirow[t]{2}{*}{$\mathrm{Xc}^{2}$} & \multicolumn{3}{|c|}{ Prediction Observation Differential } & \multirow[t]{2}{*}{$\mathrm{Xc}^{2}$} \\
\hline & value & data & value & & value & data & value & \\
\hline 30 & 13.01 & 13.03 & -0.01 & 0.0182 & 14.07 & 14.08 & -0.01 & 0.0169 \\
\hline 45 & 33.81 & 33.84 & -0.03 & 0.0065 & 33.16 & 33.18 & -0.03 & 0.0067 \\
\hline 60 & 52.22 & 52.27 & -0.05 & 0.0038 & 60.92 & 60.97 & -0.05 & 0.0034 \\
\hline 75 & 55.53 & 55.71 & -0.19 & 0.0018 & 54.98 & 54.76 & 0.22 & 0.0015 \\
\hline 90 & 58.64 & 58.99 & -0.35 & 0.0004 & 59.81 & 59.5 & 0.31 & 0.0006 \\
\hline 105 & 43.65 & 43.12 & 0.53 & 0.0245 & - & - & - & - \\
\hline $\mathrm{Xc}^{2}$ & & & & 0.0552 & & & & 0.0290 \\
\hline
\end{tabular}


Table 4 showed the comparison between simulation and observation of leaves nitrogen rate. It can be worked out that $\mathrm{X} 0.05,5^{2}=9.89>\mathrm{Xc}^{2}(0.0552,0.0290)$, which revealed that at the level of 0.05 , the differential value was not significant; that is to say, the simulation and observation of leaves nitrogen rate fit well through the model.

According to the test method of 1:1 charting, figure 1 compared the simulated value and the observed value with the leaf nitrogen content as representative, and calculated their correlation coefficient. The result showed that the correlation coefficient between simulation and observation of tobacco leaf nitrogen rate was 0.9934 . They were in good consistency.

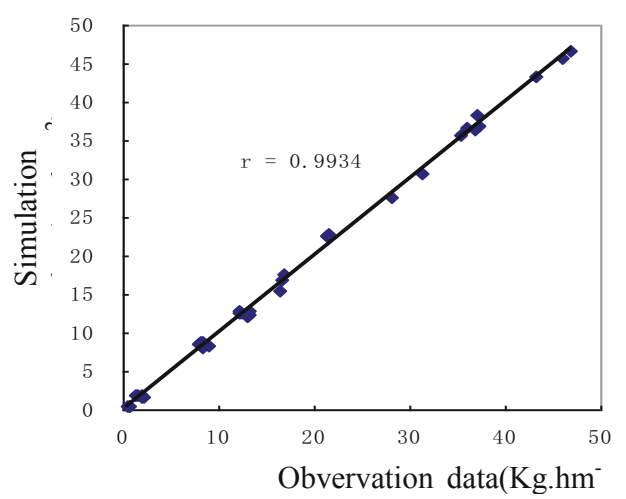

Fig. 1. Comparison between simulation and observation of leaf nitrogen rate

\section{Conclusion}

The whole growing period of tobaccos needs many nutritional elements, among which the demand for nitrogen is great. The supply of nitrogen directly influences the growth, yield and quality of tobacco. The dynamic simulation of nitrogen is a major part of crop growth simulation[14-18]. The nitrogen accumulations in roots, stems and leafs change with different growing periods. Simulating the distribution of nitrogen in tobacco plant could help us understand and learn the nitrogen content of each organ of tobacco plant. Therefore, we can adjust the amounts of nitrogenous fertilizer utilized in time and improve the yield and quality of tobacco.

Through the quantitative measurement of tobacco in different growing periods, this research concludes the pattern of tobacco's absorption of nitrogen. Establishing the nitrogen absorption and distribution models which are in dynamic changes following different growing periods can simulate the nitrogen content in each organ of tobacco plant at different growing periods. With the comparison between the simulated and observed value and their insignificant difference at the level of 0.05 shows the simulated and observed value of nitrogen contents in roots, stems and leaves of tobacco by the model are in good consistency. With the 1:1 figure comparison between the simulated and observed value with nitrogen content of tobacco as representation 
and their correlation coefficient at 0.9934 demonstrate they are consistent well. Therefore, this model is better in decision-making and adaptability and could forecast and guide the administration of nitrogenous fertilizer in the tobacco fields.

What needs explanation is that this model is the nitrogen distribution model of tobacco without consideration of the lost nitrogen following the defoliation of tobacco leaves in the late period of growing. Only by adding blade decaying rate in our later deeper researches can we describe the nitrogen content of tobacco during the whole growing periods more accurately.

\section{Acknowledgements}

This study has been funded by invitation to tender project of China State Tobacco Monopoly Administration (Contract Number: 110200201005).

\section{References}

1. Tobacco Reserch Institute of CAAS.: China Tobacco Cultivation. Shanghai Science \& Technology Press, Shanghai (2005) (in Chinese)

2. Li, C., Zang, F., Li, W., et al.: Nitrogen management and its relation to leaf quality in production of flue-cured tobacco in China. Plant Nutrition and Fertilizer Science 2, 331-337 (2007) (in Chinese)

3. Collins, W.K., Hawks Jr., S.N.: Principles of flue-cured tobacco production. North Carolina State University, Raleigh (1994)

4. Jie, X., Huang, X., Liu, S., et al.: Effect of Different Nitrogen Formson Tobacco Quality Indices. Chinese Journalof Soil Science 6, 1150-1153 (2007) (in Chinese)

5. Liu, W., Guo, Q., Wang, Q., et al.: Influence of Different Nitrogen Levels on Yield, Quality, Dry Matter and Nitrogen Accumulation and Distribution of Flue-cured Tobacco. Journal of Henan Agricultural Sciences 8, 28-28 (2004)

6. Wei, C., Qian, X., Yang, H., et al.: Studies on Nitrogen Absorption and Utilization in Tobacco. Tillage and Cultivation 3, 37-41 (1995) (in Chinese)

7. Ma, X., Zhang, Z., Rong, F., et al.: Studies on Nitrogen Absorption, Distribution and Utilization in Flue-cured Tobacco under Higher and Lower Fertility Conditions. Chinese Tobacco Science 1, 1-4 (2009) (in Chinese)

8. Ritchie, J.T.: CERES-WHEAT. Michigan State University (1988)

9. Drenth, H., Ten Berge, H.F.M.: O- RYZA simulation modules for potential and nitrogen limited rice. In: SARP Research Proceedings (1994)

10. Aggarwal, P.K.: Analyzing the limitations set by climate factors, genotype, water and nitrogen availability on productivity of wheat I. The model description, parameterization and validation. Field Crops Res. 38, 73-91 (1994)

11. Gao, L., Jin, Z., Huang, Y., et al.: Rice cultivational simulation-optimization-decision making system (RCSODS). China Agricultural Science and Technology Press, Beijing (1992)

12. Cao, H.: Studies on simulation-optimization-decision making for wheat population, soil moisture and nitrogen dynamic. Nanjing Agricultural University, Nanjing (1997)

13. Shidan, B.: Soil and Agricultural Chemistry Analysis. China Agricultural Press, Beijing (2000) (in Chinese) 
14. Yun, X., Kiniry, J.R.: A Review on the Development of Crop Modeling and its Application. Acta Agronomica Sinica 2, 190-195 (2002) (in Chinese)

15. Cao, W., Luo, W.: System Simulation and Intelligent Management for Crops. Huawen Press, Beijing (2000)

16. Luo, S., Peng, S.: Agroecosystem Analysis. Guangdong Science and Technology Press, Guangzhou (1996) (in Chinese)

17. Tian, S., Ren, Z., Bu, Y., et al.: Experimental Researches and Dynamic Modeling on the Partitioning Index of Nitrogen in Rice. Journal of Inner Mongolia University for Nationalities 5, 516-520 (2006) (in Chinese)

18. Ma, X., Shi, Y., Xi, L., et al.: Design and Implementation of a Knowledge Model System for Tobacco Nitrogen Strategies. Journal of Henan Agricultural University 1, 91-94 (2006) (in Chinese) 